\title{
Sub-specialty in neurosurgery: Time has come for Nepal
}

\author{
Amit Thapa $M C h^{1}$ iD \\ ${ }^{1}$ Department of Neurosurgery, Kathmandu Medical College Teaching Hospital, Kathmandu, Nepal \\ Date of submission: $10^{\text {th }}$ May 2021 \\ Date of acceptance: $15^{\text {th }}$ August 2021 \\ Date of publication: $1^{\text {st }}$ September 2021
}

Key words: Nepal, Neurosurgery, Sub-specialty.

With over 90 practicing neurosurgeons in the country, should we be developing sub-specialty in neurosurgery?

The number of trained manpower has risen steadily, since neurosurgery was first practiced in Nepal in $1961 .{ }^{1}$ Though we are halfway to the milestone of achieving a ratio of 1 neurosurgeon for every 1 lakh population, the situation here is much better than in other Sub-Saharan African and south east Asian countries. ${ }^{2}$ All the seven states now have neurosurgeons working in its hospitals, though most are still concentrated in the capitals and major towns.

Recently for the last five years, despite of lack of training opportunities for sub-specialty in the country, we have seen young neurosurgeons getting trained in skull base, spine, minimally invasive or endoscopic neurosurgery, functional neurosurgery, pediatric neurosurgery and vascular neurosurgery from abroad. There is a variation in nature and period of training, ranging from observership of a few weeks to fellowship of over a year. The interest seems to be getting stronger as the facilities and complexities of cases are increasing. In such scenarios, rather than few individuals we need units or teams offering these sub-specialized services from key

\section{Access this article online}

Website: https://www.nepjol.info/index.php/NJN

DOI: https://doi.org/10.3126/njn.v18i3.39183

HOW TO CITE

Thapa A. Sub-specialty in neurosurgery: Time has come for Nepal.

NJNS. 2021;18(3):1-2.

\author{
Address for correspondence: \\ Prof Amit Thapa \\ Department of Neurosurgery, \\ Kathmandu Medical College Teaching Hospital, \\ Sinamangal, Kathmandu, Nepal \\ E-mail: dramitthapa@yahoo.com \\ Phone: +977 9851177995
}

Copyright (C) 2021 Nepalese Society of Neurosurgeons (NESON)

ISSN: 1813-1948 (Print), 1813-1956 (Online)

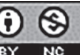

This work is licensed under a Creative Commons Attribution-Non Commercial 4.0 International License. centers and start supervised systematic training for the interested.

\section{Need and benefit of sub-specialty}

Despite refinement and improvement in the reach of neurosurgical services in Nepal, roughly $20 \%$ of neurosurgical patients are referred abroad for surgical interventions, more so in towns bordering India and China. This is largely due to lack of sub-specialty care and modern equipment for offering these services. Access to the internet has made people more aware and they are justified in seeking these services.

In absence of specialized neurosurgical units, practitioner of other specialty like radiology, plastic surgery, ophthalmology, pediatric surgery, orthopedic, anesthesia and ENT have been offering these services which is limited to certain procedures or conditions and does not provide for comprehensive care which is possible under a sub-specialty trained neurosurgeon. These encroachments of late have, however, created confusion among the patients.

Sub-specialty training would bring a new dimension in clinical and research capabilities of the trained staff. This would create a referral system, managing general cases in the community and referring complex cases to the central areas of specialization. These centers can then be equipped with expensive and most modern equipment to offer these services. This would make the investments more cost effective and avoid unnecessary referrals.

With more experience in particular subset of neurosurgical disease, evidence-based practice and guidelines could be customized according to local needs. This would also foster development of allied specialties and businesses to cater needs of the specialties. Exposure to these units would help medical graduates and postgraduates to learn more and harness their skills. With initiation of training programs like Fellowship or Post Graduate Diplomas in these units, soon all sub-specialty training could be offered in the country. 


\section{Major obstacles}

As with any new attempt, developing sub-specialty in Nepal is also mired with problems due to

- Inadequate training

- Lack of group practice

- Lack of allied support

- Poor referral pattern

- Inadequate infrastructure and lack of funds

- Inadequate medical insurance and financial capabilities of patients

- Indifference by government which prioritizes primary health care

- Mismanagement and corruption.

These are globally common problems, more so in third world countries ${ }^{1}$ compounded by the fact that here everyone is doing everything (practically non-existent referral system) and lack of medical insurance. This does not allow development of a center of excellence.

Though overcoming these hurdles may take time, this is possible with the initiation by the leaders in the neurosurgical community and support by young neurosurgeons and the trainees. The fear of losing patients as one specializes and inability to survive in a small niche are unfounded and would soon disappear once the specialist gets to see patients of their interest and offer world class superior services. As the experience develops and the results improve, the data would speak for excellence.

\section{How can this be started?}

Certainly, this is not possible in centers with one or two neurosurgeons, as they have to cater to general neurosurgery. But in big departments with four or more neurosurgeons with facilities and funds, these should be pushed by the head and chairman. Young and bright should be encouraged to take up specialty training and start practicing their interested field. They should be incentivized and a referral system within the department can be created to allow them to mature in their art.

Nepalese Society of Neurosurgeons (NESON) has taken leadership in initiating this approach. For the first time in the history of Nepal Medical Council (NMC), a professional society has approached them for starting a fellowship, this time in spine. With the support of the departments running neurosurgical courses in the country, a rotatory fellowship program is being envisioned to expose the fellow to the best and the vast experiences.

Few centers have started this homework and the future looks bright. We need sub-specialty units in vascular neurosurgery, skull base, spine, functional neurosurgery (epilepsy, movement disorders and pain), pediatric neurosurgery, neuro-critical care, minimal invasive or endoscopic neurosurgery, trauma neurosurgery and radiosurgery.

With Nepal catapulting out of least developed countries (LDC), the neurosurgical community should look beyond general neurosurgery. Rather than be jack of all, it would be great to be master of one! Time is ripe for developing sub-specialty in neurosurgery both as practice and training centers.

\section{References}

1. Roka Y. Neurosurgery in Eastern Nepal: The past, present and future and a near decade of personal experience. Nepal J Neurosci. 2017;14(2):1-2. https://doi.org/10.3126/njn.v14i2.19696

2. Shilpakar SK. Subspecialties in neurosurgery and its challenges in a developing country. World Neurosurg. 2011;75(3-4):335-7.https://doi.org/10.1016/j. wneu.2010.12.047

3. Kato Y, Liew BS, Sufianov AA, Rasulic L, Arnautovic $\mathrm{KI}$, Dong VH, et al. Review of global neurosurgery education: Horizon of Neurosurgery in the developing countries. Chin Neurosurg Jl. 2020;6:19. https://doi. org/10.1186/s41016-020-00194-1

4. Gasco J, Braun JD, McCutcheon IE, Black PM. Neurosurgery certification in member societies of the World Federation of Neurosurgical Societies: Asia. World Neurosurg. 2011;75(3-4):325-34. https://doi. org/10.1016/j.wneu.2011.01.001

5. Servadei F, Rossini Z, Nicolosi F, Morselli C, Park $\mathrm{KB}$. The role of neurosurgery in countries with limited facilities: Facts and challenges. World Neurosurg. 2018;112:315-21.https://doi.org/10.1016/j. wneu.2018.01.047

6. Robertson FC, Esene IN, Kolias AG, Khan T, Rosseau $\mathrm{G}$, Gormley WB, et al. Global perspectives on taskshifting and task-sharing in neurosurgery. World Neurosurgery.2019;X.https://doi.org/10.1016/j. wnsx.2019.100060 